\title{
Common Genetic Risk Factors for Conduct Disorder and Alcohol Dependence
}

\author{
Wendy S. Slutske \\ University of Missouri-Columbia
}

\author{
Andrew C. Heath, Stephen H. Dinwiddie, \\ Pamela A. F. Madden, and Kathleen K. Bucholz \\ Washington University School of Medicine
}

\author{
Michael P. Dunne, Dixie J. Statham, and Nicholas G. Martin \\ Queensland Institute of Medical Research
}

\begin{abstract}
The association between retrospectively reported childhood conduct disorder $(C D)$ and a history of alcohol dependence (AD) was examined in a sample of 2,682 male, female, and unlike-sex adult twin pairs. There was a strong association between $\mathrm{CD}$ and $\mathrm{AD}$ in both men (tetrachoric $r=.34$, odds ratio $=2.8$ ) and women (tetrachoric $r=.53$, odds ratio $=9.9$ ). Genetic factors accounted for most of the association between $C D$ and $A D$ liability in men and women, with the remainder of the association being due to nonshared individual-specific environmental factors. Genetic influences common to $\mathrm{CD}$ and $\mathrm{AD}$ accounted for $17 \%$ and $35 \%$ of the genetic variation in $\mathrm{AD}$ liability in men and women, respectively, and accounted for $11 \%$ and $23 \%$ of the total variation in $\mathrm{AD}$ liability in men and women, respectively. The results suggest that there are common genetic risk factors for $C D$ and $\mathrm{AD}$ or that $\mathrm{CD}$ itself is an important genetically influenced risk factor for $\mathrm{AD}$.
\end{abstract}

There is accumulating evidence from twin and adoption studies that genetic influences may account for a substantial proportion of the population variation in alcoholism risk (Heath, Slutske, \& Madden, 1997), and recent evidence suggests that genetic influences may be as important for the development of

Wendy S. Slutske, Department of Psychology, University of Missouri-Columbia; Andrew C. Heath, Stephen H. Dinwiddie, Pamela A. F. Madden, and Kathleen K. Bucholz, Department of Psychiatry, Washington University School of Medicine; Michael P. Dunne, Dixie J. Statham, and Nicholas G. Martin, Epidemiology Unit, Queensland Institute of Medical Research, Brisbane, Queensland, Australia. Stephen H. Dinwiddie is now at the Elgin Mental Health Center, Elgin, Illinois, and Michael P. Dunne is now at the Queensland University of Technology, Brisbane, Queensland, Australia.

This work was supported by National Institutes of Health (NIH) Grants AA07535, AA07728, AA10249, and AA00264, by NIH Postdoctoral Training Grants MH17104 and DA07261, and by a grant from the Australian National Health and Medical Research Council. Portions of this research were presented at the annual meeting of the Behavior Genetics Association, Pittsburgh, Pennsylvania, June 1996, and at the meeting of the Society for Research in Psychopathology, Atlanta, Georgia, September 1996. We thank Michael B. Miller for his helpful advice on model fitting, and Kenneth Leonard, Matt McGue, and Lee Robins for their comments on earlier versions of this article. We acknowledge the assistance of Laura Bierut, Randy Cates, Michael Hodge, Sue Mason, Hui Pan, Theresa Pangan, John Pearson, Pamela Saunders, Olivia Zheng, and the interviewers. We thank the twins from the Australian National Health and Medical Research Council Twin Register for their continuing cooperation.

Correspondence concerning this article should be addressed to Wendy S. Slutske, Department of Psychology, University of Missouri, $210 \mathrm{Mc}-$ Alester Hall, Columbia, Missouri 65211. Electronic mail may be sent to psycws@showme.missouri.edu. alcoholism in women as in men (Kendler, Heath, Neale, Kessler, \& Eaves, 1992; Heath, Bucholz, et al., 1997). Relatively little is known about the mechanisms by which genes increase the risk for alcoholism.

One strategy for understanding the mechanisms by which genes contribute to the liability to develop alcoholism is to examine the extent to which common genetic influences account for an observed association between another trait, such as cooccurring psychiatric disorder, and alcoholism. In a populationbased sample of over 1,000 female twin pairs, Kendler et al. (1995), using multivariate genetic and environmental structural equation modeling, showed that about $24 \%$ of the genetic variation in liability to alcoholism in women could be accounted for by genetic influences on major depression, bulimia, and the anxiety disorders (specific and social phobia, generalized anxiety, and panic disorder). This suggests that most of the genetic influences on alcoholism in women are not due to genetic influences associated with risk of depression, bulimia, and the anxiety disorders.

Rates of depression and the anxiety disorders are elevated in those with alcohol dependence $(A D)$ compared with individuals without $A D$, but the strongest observed associations between $\mathrm{AD}$ and another non-substance-related psychiatric diagnosis are with antisocial personality disorder (ASPD) and with conduct disorder (CD; Helzer \& Pryzbeck, 1988; Kessler et al., 1996; Regier et at 1990). Although it has generally been assumed that antisocial behavior is not relevant to the etiology of AD in women (e.g., Cloninger, 1987), the association between antisociality and $\mathrm{AD}$ found in epidemiological surveys appears to be even stronger among women than among men (e.g., Helzer, Burnam, \& McEvoy, 1991). Given the strong covariation between antisociality and alcoholism in both women and men, it is possible that genetic influences for CD or ASPD may also 
account for some of the genetic variation in $\mathrm{AD}$ liability in both sexes.

Results of family, adoption, and twin studies that have examined the familial association between childhood or adult antisocial behaviors and $\mathrm{AD}$ are equivocal. Most family studies that have examined this association, for example, by assessing rates of antisocial behaviors in the relatives of alcoholic adults or rates of alcoholism in the parents of children with $\mathrm{CD}$, demonstrate significant familial cross-transmission between antisocial behaviors and $\mathrm{AD}$ (Amark, 1951; Lewis, Rice, \& Helzer, 1983; Lynskey, Fergusson, \& Horwood, 1994; Stewart, deBlois, \& Cummings, 1980) but cannot resolve whether this is genetic or environmental in origin. Evidence from adoption studies suggests that the genetic transmission of antisocial behavior and $\mathrm{AD}$ are independent (Cloninger, Reich, \& Guze, 1978; Cloninger \& Reich, 1983), because a significant association between antisocial behavior in biological parents and $A D$ in their adopted-away offspring or a significant association between $\mathrm{AD}$ in biological parents and antisocial behavior in their adopted-away offspring was not observed (Cadoret, O'Gorman, Troughton, \& Heywood, 1985; Cadoret, Troughton, \& O'Gorman, 1987; Cadoret, Yates, Troughton, Woodsworth, \& Stewart, 1995; Crowe, 1974; Goodwin, Schulsinger, Hermansen, Guze, \& Winokur, 1973; Schulsinger, 1972). The few twin studies that have addressed this issue, on the other hand, have found evidence to suggest common genetic influences for antisocial behaviors and AD. In a sample of twin pairs ascertained from alcohol and drug abuse treatment programs, McGue, Pickens, and Svikis (1992) found higher scores on a CD symptoms scale in male monozygotic (MZ) cotwins of alcoholics than in male dizygotic (DZ) cotwins of alcoholics, and Pickens, Svikis, McGue, and LaBuda (1995) found higher cross-trait cross-twin correlations between diagnosed $A D$ in a twin and ASPD in the cotwin in male $M Z$ versus DZ twin pairs. Grove et al. (1990), in a small sample of $\mathrm{MZ}$ twins reared apart, found substantial overlap between the genetic influences for alcohol problems and childhood conduct problems (genetic correlation of .54) and between alcohol problems and adult antisocial behaviors (genetic correlation of .75).

Interpretation of studies of the association between adult antisocial behavior and $\mathrm{AD}$ are complicated by the fact that alcohol use itself has been demonstrated to increase aggressiveness in experimental studies (Bushman \& Cooper, 1990; Ito, Miller, \& Pollock, 1996). Thus, determining whether ASPD and AD have common etiologies can be difficult because of the possible causal effect of alcohol on aggression. By studying the association between $\mathrm{AD}$ and antisocial behaviors that occur prior to substantial alcohol exposure, such as childhood $C D$, it may be possible to test the alternative hypotheses that $C D$ causes $A D$ or that $\mathrm{CD}$ and $\mathrm{AD}$ are caused by other common risk factors, such as genes.

Twin, family, and adoption studies have been consistent in demonstrating substantial familial aggregation for childhood antisocial behaviors but have been inconsistent concerning the relative role of genes and shared family environment in the familial aggregation. Whereas some studies have found evidence for substantial genetic influences in the development of childhood antisocial behavior problems (Eaves et al., 1997; Grove et al., 1990; Rowe, 1983; Slutske et al., 1997; Twito \& Stewart, 1982), others have not (Lyons et al., 1995; see also Cloninger \&
Gottesman, 1987; DiLalla \& Gottesman, 1989). For example, in two recent twin studies of adult-reported childhood CD (the largest twin studies of $C D$ to date), the estimates of the contribution of genetic factors to variation in risk for CD were 7\% (Lyons et al., 1995) versus $43 \%-71 \%$ (Slutske et al., 1997).

In the present study, we examined the association between a history of childhood $C D$ and lifetime history of $A D$ in a large twin sample in which substantial genetic influences for CD have already been demonstrated (Slutske et al., 1997). We examined the extent to which genetic and environmental influences on the risk for $\mathrm{CD}$ can account for the genetic and environmental risk of developing $A D$ and whether this differs for men and women.

Method

\section{Participants}

The participants were from the Australian National Health and Medical Research Council Twin Register (ATR), a volunteer twin panel recruited through the media, schools, and a variety of other sources (Jardine \& Martin, 1984). Four alcohol-related studies have been carried out to date with the ATR sample: (a) a laboratory study of responses to alcohol conducted in 1978 and 1979 with a subset of the ATR sample (Heath \& Martin, 1992; Martin, Oakeshott, et al., 1985; Martin, Perl, et al., 1985); (b) a questionnaire survey mailed to all members of the ATR in 1980 and 1981 (Heath, Madden, Slutske, \& Martin, 1995; Jardine \& Martin, 1984); (c) a follow-up questionnaire survey in 1988 and 1989, mailed to all twins from pairs in which both completed questionnaires for the previous survey (Heath, Cloninger, \& Martin, 1994; Heath \& Martin, 1994); and (d) a telephone interview survey conducted in 1992 and 1993 with individuals from the laboratory study and with twin pairs in which at least one twin participated in the 1988-1989 follow-up questionnaire survey targeted for interview (Heath, Bucholz, et al., 1994). Data obtained from the telephone interview survey were analyzed for the present study.

Responses were obtained from 8,183 individuals in the 1980-1981 survey, which represented a $69 \%$ individual response rate and from 6,327 individuals in the 1988-1989 survey, which represented a $83 \%$ individual response rate. Individual response rates in twin surveys are typically lower than those obtained from unrelated individuals in community surveys, because twin pairs are correlated for cooperativeness and often consult each other before choosing to participate. For example, the pairwise response rate (i.e., percentage of twin pairs in which both twins participated) in the $1980-1981$ survey was $64 \%$; if twin participation were uncorrelated, this would have yielded an individual response rate of $80 \%$. The response rates obtained for this volunteer sample are similar to response rates obtained in other questionnaire surveys of community-based twin samples (e.g., Kendler et al., 1992; True et al., 1993).

Telephone interviews were completed with 5,889 individuals: 2,041 men (mean age $=42.7$ years, range $=28-89$ ) and 3,848 women (mean age $=44.8$ years, range $=27-90) .{ }^{1}$ After excluding twins who were deceased, had previously asked not to be contacted, were overseas, or could not be located, the cooperation rate for the telephone interview

\footnotetext{
${ }^{1}$ The reported sample size was 5,995 in some previous articles. Subsequently, we discovered that 106 individuals ( 36 twin pairs and 34 single twins) were interviewed who did not meet the criteria for inclusion in the 1992-1993 interview survey. The 106 participants had responded to mailed questionnaires of the ATR in 1980 or 1981, but had not participated (nor had their twins participated) in either the alcohol challenge study or the 1988-1989 mailed questionnaire survey. These 106 participants were excluded from the present study.
} 
was $91 \%$ in men and $92 \%$ in women. There were 2,685 complete twin pairs. After excluding three pairs in which one twin's CD diagnostic data were incomplete, there were 2,682 twin pairs available for analysis ( 930 female MZ twin pairs, 396 male MZ twin pairs, 533 femalefemale DZ twin pairs, 231 male-male DZ twin pairs, and 592 femalemale $D Z$ twin pairs).

A number of checks were done to examine biases in the sample at each stage of assessment. Comparison with national norms, when available, provided a check on sampling bias. Yet another check on sampling bias exploited the longitudinal follow-up of the sample by comparing characteristics of those who were successfully followed up with those who were not. Twin data can provide additional information on possible sampling biases over and above that available for surveys of unrelated individuals. Given that twins are correlated for a trait, bias in the sample is reflected in differences between the cotwins of participating and nonparticipating individuals. Having twins report about their cotwins provides a more direct assessment of the characteristics of the nonparticipating cotwins of participants. Briefly, the most substantial and consistent biases in the sample were the over-representation of women and $M Z$ twins, a characteristic of most volunteer twin samples, and the underrepresentation of the oldest twins because of infirmity or death. In addition, participants with higher educational attainments were overrepresented. However, compared with a national survey of drinking practices, the alcohol use of the male participants was similar to that of the general population of Australia, whereas female heavier drinkers were over-represented (Jardine \& Martin, 1984). Personality traits, as measured by the revised Eysenck Personality Questionnaire scales (Eysenck, Eysenck, \& Barrett, 1985), did not appear to be strongly or consistently associated with study participation.

Further checks were carried out to determine the representativeness of the ATR with respect to $C D$ and $A D$ assessed at the telephone interview (Heath, Bucholz, et al., 1997; Slutske et al., 1997). If twins with $\mathrm{CD}$ or $\mathrm{AD}$ were less likely to be included in the sample, then a higher prevalence of these disorders would be observed in twins whose cotwins did not participate in the interview compared with the prevalence observed in twins whose cotwins did participate. The rates of $C D$ and $A D$ among the 519 twins whose cotwins did not participate in the interview did not differ significantly from the rates among the twins concordant for participation, which suggests that this sample is not biased with respect to $C D$ and $A D$.

Nonetheless, concerns remained regarding the representativeness of the interviewed sample. Heath et al. (1996, 1998; Heath, Bucholz, et al., 1997) examined the impact of cooperation bias and attrition on rates of $C D$ and $A D$ and estimates of genetic and environmental influences on $C D$ and $A D$ liability by weighting the interview data to reflect (a) the distribution of educational attainment found in the general population of Australia, which was based on published national norms, and (b) the demographic and personality characteristics of all of the participants who took part in the first questionnaire survey in 1980 and 1981. The rates of $C D$ and $A D$ in the weighted data were very similar to the unweighted rates. Therefore, the over-representation of more highly educated respondents and sample attrition do not appear to have led to an under- or over-representation of individuals with $\mathrm{CD}$ or $\mathrm{AD}$. Furthermore, twin correlations were nearly identical with the weighted and unweighted $C D$ and $A D$ data. The analyses of Heath et al. (1996, 1998; Heath, Bucholz, et al., 1997) suggest that sampling bias should not have substantially affected the results of this study. One possible exception, however, is that severe cases of $\mathrm{CD}$ or $\mathrm{AD}$, or those with co-occurring $\mathrm{CD}$ and $\mathrm{AD}$, may have been under-represented in this community-based sample, a possibility that is quite likely but difficult to assess. If severe $C D$ or $A D$ or co-occurring $C D$ and $A D$ are etiologically distinct from less severe $\mathrm{CD}$ or $\mathrm{AD}$, this may have affected the results of the present study.

\section{Measures}

Zygosity. Twin zygosity diagnoses were mainly based on questionnaire responses concerning physical similarity and how often the twins were mistaken for each other as children. This method of zygosity diagnosis has been shown to be about $95 \%$ accurate, as validated against blood typing (Eaves, Eysenck, \& Martin, 1989). In addition, however, pairs in which the zygosity was ambiguous or in which there was disagreement between cotwins were followed-up for further information, and in many cases twins were asked to provide photographs to assist in assigning zygosity. There was perfect agreement between the final zygosity diagnoses and the zygosity assignment based on eight DNA microsatellite markers in 190 same-sex twin pairs from the present study (Duffy, 1994).

Conduct disorder. The Semi-Structured Assessment for the Genetics of Alcoholism interview (SSAGA; Bucholz et al., 1994), originally developed for the Collaborative Study on the Genetics of Alcoholism (COGA), was modified for use as a telephone interview in Australia. Interviews were administered by trained lay interviewers who were unaware of the psychiatric status of the cotwin. Interviewers were supervised by a project coordinator, a qualified clinical psychologist with 4 years of experience. All interview protocols were reviewed either by the project coordinator or by the most skilled interviewers (those who maintained consistently low error rates in coding); the reviews were always done by someone other than the person who conducted the interview. In addition, all interviews were tape-recorded, and a random sample of interview tapes were reviewed for quality control and coding inconsistencies.

Individual CD symptoms were assessed by telephone interview with the modified SSAGA. The individual CD symptoms were aggregated into a lifetime $\mathrm{CD}$ diagnosis by a computer algorithm. Two definitions of $\mathrm{CD}$, corresponding to the definition of $\mathrm{CD}$ in the Diagnostic and Statistical Manual of Mental Disorders (3rd ed., rev.; DSM-III-R; American Psychiatric Association, 1987; endorsement of three or more CD symptoms occurring at any time prior to age 18 ) and to the childhood criterion for $D S M-I I I-R$ antisocial personality disorder (endorsement of three or more CD symptoms occurring at any time prior to age 15 ), were used in the present study. The rates of these two definitions of $C D$ in this sample were $18 \%$ and $13 \%$, respectively, in men and $3 \%$ and $2 \%$, respectively, in women (Slutske et al., 1997). Unless specified, analyses were conducted with the broader definition of CD because of increased statistical power, and analyses using the narrower definition of $C D$ were conducted to rule out possible causal and noncausal explanations for the association between $\mathrm{CD}$ and $\mathrm{AD}$.

The 1-week interrater test-retest reliability of narrow $C D$, assessed by the SSAGA interview, was .64- .65 indexed by Yule's $Y$ (Spitznagel \& Helzer, 1985) and was .80-.82 indexed by the tetrachoric correlation (unpublished data from Bucholz et al., 1994). Stability of retrospective reports of childhood $C D$ was examined in 604 participants from the present study who were reinterviewed (by telephone or personal interview) an average of 15 months later (range $=2-24$ months). The stability of narrow $\mathrm{CD}$, as indexed by Yule's $Y$ and the tetrachoric correlation, was .76 and .83 , respectively, and was .67 and .78 , respectively, for broad CD (Slutske et al., 1997). The 15-month stability of the retrospective reports of childhood $C D$ assessed in these adult participants was as high as the short-term reliabilities obtained for the SSAGA interview.

Alcohol dependence. Individual $\mathrm{AD}$ symptoms were assessed by telephone interview and aggregated into lifetime $D S M-I I I-R$ diagnoses by computer algorithm. In this sample, the $D S M-I I I-R$ definition yielded $A D$ rates of $24 \%$ in men and $6 \%$ in women (Heath, Bucholz, et al., 1997). The 1-week interrater test-retest reliability of $A D$ assessed by the original SSAGA interview was $.87-.90$ indexed by Yule's $Y$ (Bucholz et al., 1994). Tetrachoric correlations for this same definition of $\mathrm{AD}$ were .97-.99 (unpublished data from Bucholz et al., 1994). 
Heath, Bucholz, et al. (1997) obtained a tetrachoric correlation of .77 between independent interview assessments of $A D$ conducted, on average, 1-3 years apart with 1,117 female twins from the present study. The reliability of lifetime diagnoses of $A D$ is very high and exceeds that of most other psychiatric diagnoses (Slutske et al., 1998).

For each symptom of $A D$ endorsed, the age of onset of the symptom was obtained. The age of onset of $A D$, for the purposes of this study, was defined as the age at which the participant first had symptoms from three or more $D S M-I I I-R$ symptom groups (i.e., the first age that the participant could have met the diagnostic criteria for $\mathrm{AD}$ ). Participants were also asked the age at which they first drank at least once a month for 6 months or more, the age at which they first got drunk, and whether they had gotten drunk more than once before the age of 15 . Although retrospective reports of the lifetime occurrence of psychiatric symptoms can be obtained with good reliability, the age of onset of occurrence is not reported with as high a reliability. Retrospectively reported ages of onset in the present study should be interpreted with caution.

\section{Data Analysis}

In univariate model fitting of twin data, the variation in liability for a single trait is partitioned into that due to additive genetic influences (A), shared environmental influences (C), and nonshared environmental influences and measurement error (E). In bivariate model fitting of twin data, this is done for each of two traits, and in addition, the correlation between the two traits is similarly decomposed into that portion that is due to additive genetic influences, shared environmental influences, and nonshared environmental influences (and measurement error that is correlated in the two traits).

For each of the five Sex $\times$ Zygosity groups, a $4 \times 4$ matrix of tetrachoric correlations was generated by the method of maximum likelihood using PRELIS (Jöreskog \& Sörbom, 1988). The tetrachoric correlation (Olsson, 1979), or correlation in liability, is used when one assumes that scores on the observed ordinal variables can be explained by underlying, normally distributed latent variables. For the present study, we assumed that there were normally distributed continua of liability underlying the categorical diagnoses of $\mathrm{CD}$ and $\mathrm{AD}$ (Falconer, 1965; Gottesman \& Shields, 1967; Reich, Cloninger, \& Guze, 1975). This assumption has been tested for CD (Slutske et al., 1997) and AD (Kendler et al., 1992), and in neither case could it be rejected.

Two elements of the matrices of tetrachoric correlations were the within-trait cross-twin correlations for $\mathrm{CD}$ and $\mathrm{AD}$. Bivariate analyses require four additional correlations: (a) two cross-trait within-twin correlations between $\mathrm{CD}$ and $\mathrm{AD}$ for each twin from a pair in twins randomly designated as the first and second twins and (b) two cross-trait cross-twin correlations between $\mathrm{CD}$ and $\mathrm{AD}$, first of $\mathrm{CD}$ status in the first twin with $A D$ status in the second twin and then of $A D$ status in the first twin with CD status in the second twin.

When twin data for a single trait are analyzed, the within-trait crosstwin correlations are compared in $\mathrm{MZ}$ and $\mathrm{DZ}$ twins. When data are collected for two or more traits, one can make similar inferences about the source of the correlation between traits by comparing the cross-trait cross-twin correlations in $\mathrm{MZ}$ and $\mathrm{DZ}$ twins in relation to the crosstrait within-twin correlation between the two traits. Thus, if the MZ cross-trait cross-twin correlation between $C D$ and $A D$ is nearly as large as the cross-trait within-twin correlation between $C D$ and $A D$, this would suggest that there are important familial factors (either genetic or environmental) that are causing the correlation between the traits. The magnitude of the $\mathrm{DZ}$ relative to the $\mathrm{MZ}$ cross-trait cross-twin correlation determines the relative importance of genetic versus shared environmental factors in explaining the correlation between the traits. If the DZ cross-trait cross-twin correlation between $C D$ and $A D$ is lower than the MZ cross-trait cross-twin correlation, this would suggest that genetic influences (at least partially) explain the correlation between CD and

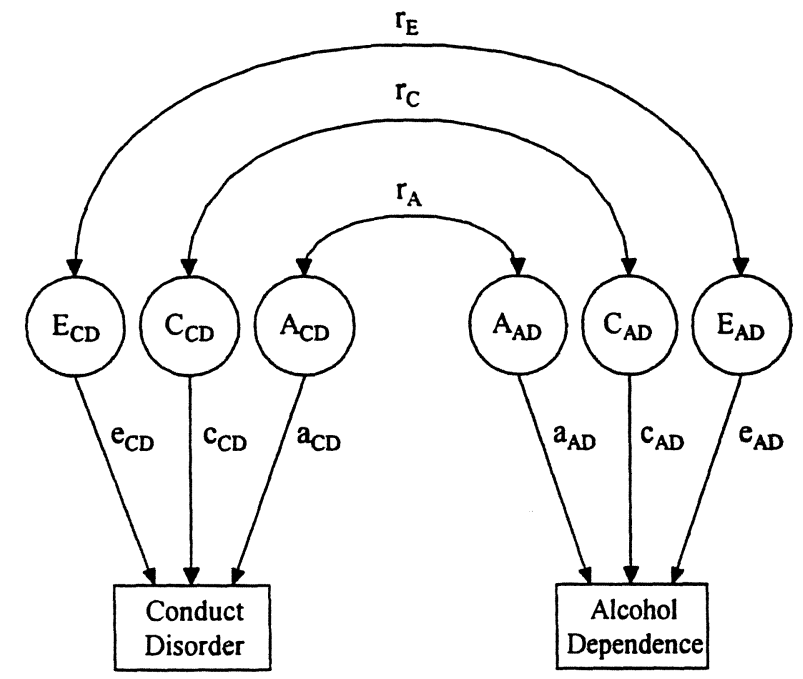

Figure 1. Path diagram of the association between conduct disorder (CD) and alcohol dependence (AD) for a single individual. The variance in liability for $C D$ and $A D$ is decomposed into that due to the effects of additive genetic influences $(A)$, shared environmental influences $(C)$, and nonshared environmental influences, including measurement error $(E)$. The paths with single arrows $(a, c$, and $e)$ from the latent genetic, shared environmental, and nonshared environmental effects to the traits of $C D$ and $A D$, when squared, yield the proportion of variation in liability to $C D$ and $A D$ attributable to that source. The correlation between $\mathrm{CD}$ and $\mathrm{AD}$ liability is similarly decomposed into that due to additive genetic influences $\left(r_{A}\right)$, shared environmental influences $\left(r_{C}\right)$, and nonshared environmental influences $\left(r_{E}\right)$.

$A D$. Conversely, if the $\mathrm{DZ}$ cross-trait cross-twin correlation between $C D$ and $A D$ is nearly as large as the $M Z$ cross-trait cross-twin correlation, then shared environmental factors may be important in causing the correlation between $\mathrm{CD}$ and $\mathrm{AD}$. (For further explanation of multivariate genetic analysis, see Carey \& DiLalla, 1994.)

Genetic and environmental models were fitted to the five twin correlation matrices and to the corresponding asymptotic covariance weight matrices by the method of weighted least squares, using the $\mathrm{Mx}$ program (Neale, 1995). The fit of a series of nested submodels was compared by likelihood-ratio chi-square to the most general full model, illustrated for a single individual in Figure 1, which allowed for additive genetic, shared environmental, and nonshared environmental factors as sources of variation for and covariation between the liability to $C D$ and $A D$. For example, models in which the genetic influences were fixed at 0 were compared with the model containing all three sources of variation. When dropping parameters from a model did not result in a statistically significant decrement in model fit (i.e., there was a nonsignificant likelihoodratio chi-square test), then the reduced model was considered to give a better (i.e., more parsimonious) fit to the data. The following questions were evaluated using the likelihood-ratio chi-square test: (a) whether the parameter estimates from the model illustrated in Figure 1 were significantly different for men and women, (b) whether the magnitude of genetic (or shared environmental) influences for $C D$ and $A D$ (i.e., paths $a_{C D}$ and $a_{A D}$ or $c_{C D}$ and $c_{A D}$ from Figure 1) differed significantly from $0,(c)$ whether the genetic or environmental correlations between $\mathrm{CD}$ and $\mathrm{AD}$ (i.e., paths $r_{A}, r_{C}$, or $r_{E}$ from Figure 1) differed significantly from 0 , and (d) whether the genetic or environmental correlations between $\mathrm{CD}$ and $\mathrm{AD}$ differed significantly from 1 . Selected as the final best-fitting model was the simplest model that was consistent with the 
data (see Heath, Neale, Hewitt, Eaves, \& Fulker, 1989; Neale \& Cardon, 1992, for further details about model fitting).

The overall adequacy of the fit of a particular model to the data was assessed by the goodness-of-fit chi-square test. Unlike most significance testing in psychological research, the goal is to obtain a nonsignificant goodness-of-fit chi-square; this indicates that the model cannot be rejected because it provides an adequate explanation of the covariance structure in the data.

\section{Results}

\section{Association Between $C D$ and $A D$}

There was a strong association between $C D$ and a lifetime history of $\mathrm{AD}$ in both men (tetrachoric $r=.34, p<.001$ ) and women (tetrachoric $r=.53, p<.001$ ). ${ }^{2}$ The rate of $\mathrm{AD}$ in men with $C D$ was $41 \%$, compared with a rate of $20 \%$ in men without a history of $\mathrm{CD}$ (odds ratio $=2.8, p<.001$ ), and the rate of $A D$ in women with $C D$ was $34 \%$, compared with a rate of $5 \%$ in women without a history of $C D$ (odds ratio $=9.9, p$ $<.001$ ). The associations were equally strong between narrow $\mathrm{CD}$ and $\mathrm{AD}$ (men: $r=.35$, odds ratio $=3.0, p<.001$; women: $r=.47$, odds ratio $=8.3, p<.001$ ).

Subsyndromal levels of $\mathrm{CD}$ symptoms were also associated with $\mathrm{AD}$; in women, a single symptom of $\mathrm{CD}$ was associated with a significant increase in the rate of $A D$, and in men, two symptoms significantly increased the rate of AD. Although only a minority of men and women in the sample had diagnosable CD (18\% and $3 \%$, respectively), many more had enough CD symptoms to significantly increase their risk of $\mathrm{AD}$ (33\% and $29 \%$, respectively).

\section{Temporal Sequence of $C D$ and $A D$ Onset}

The median retrospectively reported age of onset of $A D$ was 18 years in both men and women (men: $M=18.2, S D=3.0$, range $=10-35$; women: $M=20.9, S D=6.8$, range $=10$ 56). ${ }^{3}$ Ages of onset of $C D$ were not obtained, so it was not possible to determine the number of individuals who exhibited $C D$ prior to the onset of $A D$ and the number who had $A D$ prior to the onset of $\mathrm{CD}$. However, we could identify individuals whose $C D$ onset most likely preceded their $A D$ onset because they met diagnostic criteria for $C D$ but not $A D$ prior to age 18 or because they met criteria for $C D$ but not $A D$ prior to age 15 . As many as $55 \%$ of the men and $52 \%$ of the women with both disorders could have had an $\mathrm{AD}$ onset prior to the onset of broad $C D$. When examining the association between broadly defined $C D$ and $A D$, it is unclear whether some of the $C D$ behaviors may have occurred while the individual was under the influence of alcohol. Thus, it is possible that the association between $C D$ and $A D$ was in part spurious (i.e., the same behavior sometimes contributed to symptoms for both diagnoses) or that $A D$ was causing $C D$ in many cases.

Nevertheless, in the majority of individuals with both CD before age 15 and $A D$, the onset of $A D$ followed the onset of $\mathrm{CD} ; 88 \%$ of men and $81 \%$ of women with both disorders had an $A D$ onset after age 15 . In addition, most participants with this definition of $C D$ had only minimal exposure to alcohol before age 15 . The association between $\mathrm{CD}$ before age 15 and $\mathrm{AD}$ is unlikely to have been spurious or due to the causal influ- ence of $\mathrm{AD}$ (or heavy alcohol use) on $\mathrm{CD}$. Thus, comparing the results of the association between $C D$ and $A D$ for the two definitions of $C D$ (with an onset prior to age 18 and prior to age 15 ) should help to sort through various causal interpretations.

\section{Cross-Twin Correlations Between $C D$ and $A D$}

Cross-twin correlations between $\mathrm{CD}$ and $\mathrm{AD}$ are presented in Table 1. For men, the within-twin correlation between $C D$ and $\mathrm{AD}$ was .38 among $\mathrm{MZ}$ twins and .33 among same-sex $\mathrm{DZ}$ twins; the correlation between $C D$ in a twin and $A D$ in his cotwin was .29 for MZ twin pairs, and only .05 for $\mathrm{DZ}$ twin pairs (.29 vs. .05$), \chi^{2}(1)=4.63, p=.03$. The high $\mathrm{MZ}$ and low DZ cross-twin correlations relative to the magnitude of the within-twin correlation suggested that the co-occurrence between $C D$ and $A D$, at least in men, was mostly genetically mediated. In women, there was a large within-twin correlation of .52 among $\mathrm{MZ}$ twins and .59 among same-sex $\mathrm{DZ}$ twins between $C D$ and $A D$, but there were nearly equal cross-trait cross-twin correlations of .35 and .27 for $\mathrm{MZ}$ and $\mathrm{DZ}$ twin pairs, respectively, $\chi^{2}(1)=0.31, p=.58$. This pattern suggested that environmental factors, both shared and not shared by members of a twin pair, may be important in the covariation between CD and $A D$ in women. The different patterns observed in male and female twin pairs suggest that the sources of co-occurrence of $C D$ and $A D$ in men and women may differ. The correlations for narrow $C D$ were similar to those presented in Table 1 for $C D$ with an onset before age 18 .

Examining the unlike-sex DZ cross-twin correlation provides a test of the hypothesis of sex differences in the sources of covariation between $\mathrm{CD}$ and $\mathrm{AD}$. If the causes of covariation between $C D$ and $A D$ differ in men and women, then the unlikesex DZ cross-trait cross-twin correlation should be lower than the cross-trait cross-twin correlations found in same-sex DZ twin pairs. The DZ unlike-sex cross-trait cross-twin correlation of .13 was in between the values of .05 and .27 observed in same-sex DZ male and female pairs, respectively, and suggested that the causes of covariation between $C D$ and $A D$ may not differ substantially in men and women. Rigorous model-fitting methods, which simultaneously consider and correctly weight all of the information in the data, tested whether the pattern of correlations for same-sex male, same-sex female, and unlikesex twin pairs was consistent with the hypothesis of sex differences in the sources of covariation between $C D$ and $A D$.

\footnotetext{
${ }^{2}$ Individuals within twin pairs were treated as individual participants in the analyses of the association between $C D$ and $A D$. Parameter estimates (e.g., correlations, odds ratios) are unbiased in such analyses, but because observations from twins are not independent, the sampling variance of parameter estimates are underestimated; therefore, Type I error rates may be inflated. In the Association Between $C D$ and $A D$ section, a conservative approach was used to correct for this potential bias by dividing the original sample size by 2 to approximate the number of independent observations. The $p$ values associated with this more conservative approach are also presented in this section.

${ }^{3}$ Kessler et al. (1997), using a similar method to diagnose and calculate the age of onset of $D S M-I I I-R \mathrm{AD}$, also obtained a median age of onset of 18 years in a general population survey in the U.S.
} 
Table 1

Within-Trait and Cross-Trait Tetrachoric Correlations for Childhood Conduct Disorder (CD) and Alcohol Dependence (AD) in Australian Male and Female Twins

\begin{tabular}{|c|c|c|c|c|c|c|c|c|c|}
\hline \multirow[b]{3}{*}{ Zygosity group } & \multirow[b]{3}{*}{$n$ pairs } & \multicolumn{4}{|c|}{ Within trait } & \multicolumn{4}{|c|}{ Cross trait ${ }^{2}$} \\
\hline & & \multicolumn{2}{|c|}{$\mathrm{CD}$} & \multicolumn{2}{|c|}{$\mathrm{AD}$} & \multicolumn{2}{|c|}{ Within twin } & \multicolumn{2}{|c|}{ Cross twin } \\
\hline & & $r$ & $S E$ & $r$ & $S E$ & $r$ & $S E$ & $r$ & $S E$ \\
\hline $\mathrm{MZ}$ male & 396 & .70 & .06 & .68 & .06 & .38 & .06 & .29 & .07 \\
\hline $\mathrm{DZ}$ male & 231 & .37 & .12 & .20 & .12 & .33 & .08 & .05 & .09 \\
\hline MZ female & 930 & .68 & .10 & .58 & .08 & .52 & .08 & .35 & .10 \\
\hline DZ female & 533 & .48 & .16 & .29 & .14 & .59 & .08 & .27 & .12 \\
\hline DZ unlike sex & 592 & .34 & .12 & .43 & .09 & $.35^{b}$ & .07 & .13 & .08 \\
\hline & & & & & & $.48^{c}$ & .13 & & \\
\hline
\end{tabular}

Note. $\mathrm{MZ}=$ monozygotic; $\mathrm{DZ}=$ dizygotic.

axcept for the within-twin correlations in DZ unlike-sex pairs, the within-twin tetrachoric correlations and cross-twin correlations for first and second twins (i.e., of CD status in the first twin with $A D$ status in the second twin and of $\mathrm{AD}$ status in the first twin with $\mathrm{CD}$ status in the second twin) were pooled together to simplify presentation, because none of the correlations for first and second twins were significantly heterogeneous. ${ }^{b}$ Men. ${ }^{c}$ Women.

\section{Bivariate Model Fitting of the Association Between CD and $A D$}

The results of bivariate model fitting of the association between $\mathrm{CD}$ and $\mathrm{AD}$ are presented in Table 2. The parameter estimates from a full model are shown in Figure 2. The paths with single arrows from the latent genetic effects and nonshared environmental effects to the traits of $C D$ and $A D$, when squared, yield the proportion of variation in liability to $C D$ and $A D$ attributable to that source. Therefore, according to this model, additive genetic influences accounted for $56 \%-74 \%$, shared environmental influences accounted for $0 \%-12 \%$, and nonshared environmental influences accounted for $26 \%-37 \%$ of the variation in $\mathrm{CD}$ and $\mathrm{AD}$ liability in men and women. The correlation between genetic risk factors for $C D$ and $A D$ was .59 in men and .71 in women, the correlation between shared environmental risk factors for $C D$ and $A D$ in both men and women was -1.0, and the correlation between nonshared environmental risk factors for $C D$ and $A D$ was .26 in men and .46 in women. Because shared environmental influences contributed only a small portion of the variation in liability to $C D$ and $A D$, the perfect negative correlation between these risk factors is not particularly meaningful and so should not be accorded theoretical significance. ${ }^{4}$ The full model fit the data well: goodness-of-fit $\chi^{2}(16)$ $=18.21, p=.31 .^{5}$

The hypothesis of no sex differences in the parameter estimates was not rejected (Model 2 vs. 1 in Table 2). The hypothesis of no shared environmental influences also could not be rejected (Model 3 vs. 2), but the hypothesis of no genetic influences was rejected (Model 4 vs. 2). A model that included genetic and nonshared environmental influences as sources of variation and covariation for $C D$ and $A D$ liability was used as a base model against which to test hypotheses about the genetic and nonshared environmental correlations between the liability to $C D$ and $A D$. The hypothesis that the genetic correlation between $C D$ and $A D$ was zero was rejected (Model 5 vs. 3), as was the hypothesis that the genetic risk factors for $C D$ and $A D$ were perfectly correlated (Model 6 vs. 3). Similar hypotheses concerning the nonshared environmental correlation between $\mathrm{CD}$ and $\mathrm{AD}$ liability were also rejected (Models 7 and 8 vs. 3 ).

The model fitting had thus far indicated that Model 3 in Table 2 provided the best fit to the data. This model suggested that there were no sex differences in the sources of variation for and covariation between $C D$ and $A D$ liability and that the genetic correlation between $C D$ and $A D$ was significantly greater than 0 and significantly less than 1 . When the model fitting was repeated for $C D$ with an onset prior to 15 , the same result was obtained.

\section{Sex Differences in the Causes of Covariation Between $C D$ and $A D$}

For both definitions of $\mathrm{CD}$ used in the present study, the magnitude of the association with $\mathrm{AD}$ was significantly greater in women than in men, and some of the descriptive data presented in Table 1 suggested that the mechanisms explaining the covariation between $\mathrm{CD}$ and $\mathrm{AD}$ may differ in men and women. However, there was no evidence for sex differences in the causes of variation in and covariation between $C D$ and $A D$ in the

\footnotetext{
${ }^{4}$ When the same full model was fit to the data on narrow $C D$ and $A D$, the estimated correlation between shared environmental risk factors for the two disorders was large but positive in both men $\left(r_{c}=.88\right)$ and women $\left(r_{c}=.96\right)$.

${ }^{5}$ The effect of birth cohort (higher rates of $\mathrm{CD}$ and $\mathrm{AD}$ in those more recently born) accounted for a significant portion of the variation in $C D$ and $A D$ risk and the covariation between the disorders. Birth cohort accounted for $2 \%$ and $6 \%$ of the variation in CD risk and accounted for $2 \%$ and $5 \%$ of the variation in $A D$ risk in men and women, respectively. Of the association between $C D$ and $A D, 5 \%$ in men and $10 \%$ in women was accounted for by birth cohort effects. Because the estimates of other parameters were not substantially altered when the effect of birth cohort was excluded, we present models without birth cohort effects to simplify presentation.
} 
Table 2

Bivariate Model-Fitting Results for Conduct Disorder and Alcohol Dependence

\begin{tabular}{|c|c|c|c|c|c|c|c|}
\hline \multirow[b]{2}{*}{ Model } & \multicolumn{3}{|c|}{ Goodness-of-fit test } & \multirow{2}{*}{$\begin{array}{l}\text { Models } \\
\text { compared }\end{array}$} & \multicolumn{3}{|c|}{ Likelihood-ratio test } \\
\hline & $x^{2}$ & $d f$ & $p$ & & $\chi^{2}$ & $d f$ & $p$ \\
\hline 1. Full model, ACE, all sex-specific par. & 18.21 & 16 & .31 & & & & \\
\hline 2. ACE, no sex-specific par. & 30.64 & 23 & .13 & 2 vs. 1 & 12.43 & 7 & .09 \\
\hline 3. AE, no sex-specific par. & 30.91 & 26 & .23 & 3 vs. 2 & 0.27 & 3 & .97 \\
\hline 4. CE, no sex-specific par. & 62.12 & 26 & $<.001$ & 4 vs. 2 & 31.28 & 3 & $<.001$ \\
\hline 5. AE, no sex-specific par., $r_{\mathrm{A}}=0$ & 86.18 & 27 & $<.001$ & 5 vs. 3 & 55.27 & 1 & $<.001$ \\
\hline 6. AE, no sex-specific par., $r_{A}=1$ & 84.55 & 27 & $<.001$ & 6 vs. 3 & 53.64 & 1 & $<.001$ \\
\hline 7. AE, no sex-specific par., $r_{E}=0$ & 38.74 & 27 & .07 & 7 vs. 3 & 7.83 & 1 & .005 \\
\hline 8. $\mathrm{AE}$, no sex-specific par., $r_{\mathrm{E}}=1$ & 50.08 & 27 & .004 & 8 vs. 3 & 19.17 & 1 & $<.001$ \\
\hline 9. AE, all sex-specific par. & 20.01 & 22 & .58 & 9 vs. 3 & 10.90 & 4 & .03 \\
\hline 10. Best-fitting model, $\mathrm{AE}$, sex-specific $r_{\mathrm{A}}$ and $r_{\mathrm{E}}$ & 20.23 & 24 & .68 & 10 vs. 9 & 0.22 & 2 & .90 \\
\hline 11. AE, sex-specific $r_{\mathrm{A}}$ & 21.21 & 25 & .68 & 11 vs. 10 & 0.98 & 1 & .32 \\
\hline 12. AE, sex-specific $r_{\mathrm{E}}$ & 22.40 & 25 & .61 & 12 vs. 10 & 2.17 & 1 & .14 \\
\hline
\end{tabular}

Note. $\mathrm{A}=$ additive genetic effects; $\mathrm{C}=$ shared environmental effects; $\mathrm{E}=$ nonshared environmental effects; par. $=$ parameters; $r_{\mathrm{A}}=$ the correlation between additive genetic effects for conduct disorder and alcohol dependence liability; $r_{\mathrm{E}}=$ the correlation between nonshared environmental effects for conduct disorder and alcohol dependence liability.

bivariate model-fitting analyses presented above. Nonetheless, sex-specific models of the association between $C D$ and $A D$ were examined further for several reasons. First, the question of sex differences was of particular interest. Second, the likelihoodratio chi-square test comparing the adequacy of a model that equated parameters in men and women to a sex-limitation model approached statistical significance $(p=.09$; see Table 2$)$. Third, failure to find evidence for sex differences may have been due to a lack of statistical power.

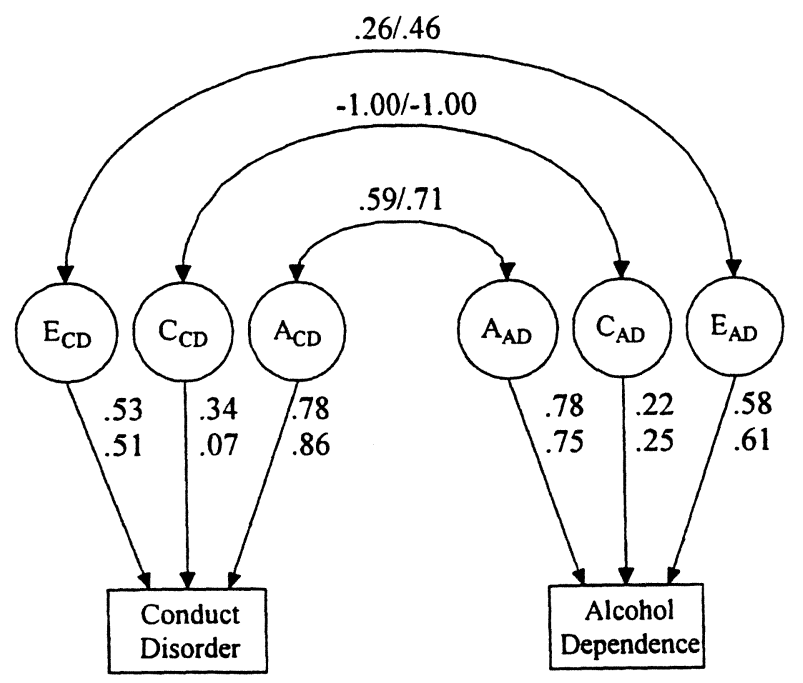

Figure 2. Parameter estimates from a full model of the association between conduct disorder (CD) and alcohol dependence (AD). The paths with single arrows from the latent genetic effects $(A)$, shared environmental effects $(C)$, and nonshared environmental effects $(E)$ to the traits of $C D$ and $A D$, when squared, yield the proportion of variation in liability to $\mathrm{CD}$ and $\mathrm{AD}$ attributable to that source. Parameter estimates for men are given on the left or top, and parameter estimates for women are given on the right or bottom.
Model fitting was repeated, this time allowing sex differences to remain while testing whether additive genetic and shared environmental parameters were necessary to aceount for the covariance structure for each sex. In both men and women, shared environmental influences, but not additive genetic influences, could be dropped from the model without a significant decrement in the model fit (Model 9 in Table 2). The relative contribution of additive genetic and nonshared environmental influences as sources of variation for $C D$ and $A D$ were very similar in men and women, but the genetic and environmental correlations between $\mathrm{CD}$ and $\mathrm{AD}$ were larger in women than in men. When this model was compared with a model that equated all parameters in the model across the sexes, there was then a significant deterioration in model fit (Model 9 vs. 3 ). Thus, this alternative approach to selecting a model suggested that there were important sex differences in the sources of variation for or covariation between liability to $C D$ and $A D$.

Further model fitting suggested that the sources of variation for $C D$ and $A D$ did not differ in men and women (Model 10 vs. 9) and that either the nonshared environmental correlation (Model 11 vs. 10) or the genetic correlation (Model 12 vs. 10) but not both (Model 3 vs. 10), likelihood-ratio $\chi^{2}(2)=10.68$, $p=.005$, could be equated in men and women without a significant deterioration in model fit. Because of the similarity in the fit of Models 11 and 12, it was not possible to resolve whether the larger correlation between $C D$ and $A D$ in women than in men was due to correlated genetic or nonshared environmental factors; therefore, Model 10 in Table 2 was judged the bestfitting model in terms of fit, parsimony, and lack of arbitrariness. Parameter estimates from this model are shown in Figure 3. According to this model, additive genetic influences in both men and women accounted for $73 \%$ and $66 \%$, respectively, and nonshared environmental influences accounted for $27 \%$ and $34 \%$, respectively, of the variation in $\mathrm{CD}$ and $\mathrm{AD}$ liability. The correlation between genetic risk factors for $\mathrm{CD}$ and $\mathrm{AD}$ was .41 (95\% confidence interval $[\mathrm{CI}]=.27-.56)$ in men and $.59(95 \% \mathrm{CI}$ $=.40-.78)$ in women, and the correlation between nonshared 


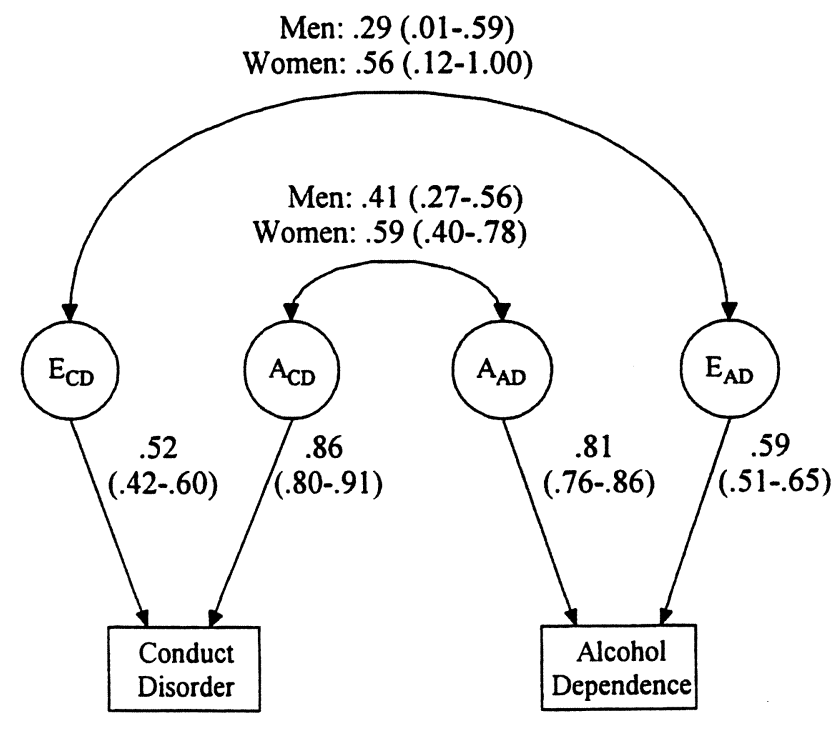

Figure 3. Best-fitting model of the association between conduct disorder (CD) and alcohol dependence (AD). Parameter estimates for men and women did not significantly differ unless separate estimates are provided. The $95 \%$ confidence intervals around parameter estimates are in parentheses. Path coefficients (and upper and lower confidence limits) can be squared to yield the proportion of variation in liability to $C D$ and $\mathrm{AD}$ attributable to genetic $(A)$ and environmental $(E)$ factors.

environmental risk factors for $\mathrm{CD}$ and $\mathrm{AD}$ was $.29(95 \% \mathrm{CI}=$ $.01-.59)$ in men and $.56(95 \% \mathrm{CI}=.12-1.00)$ in women. As can be seen from the $95 \%$ CIs, when the genetic and environmental correlations were allowed to vary for men and women, the hypothesis that the nonshared environmental factors contributing to $\mathrm{CD}$ and $\mathrm{AD}$ liability are perfectly correlated could not be rejected in women but could be rejected in men. When the same model fitting was conducted to examine possible sex differences in the sources of variation in and covariation between narrow $C D$ and $A D$, there was still no evidence for sex differences.

\section{Discussion}

The causes of covariation between $\mathrm{CD}$ and $\mathrm{AD}$ were examined in a large community-based sample of adult Australian twins. The results were consistent with earlier reports using the same sample (Heath, Bucholz, et al., 1997; Slutske et al., 1997) that suggested that the variation in liability to both $C D$ and $\mathrm{AD}$ was best accounted for by additive genetic and nonshared environmental effects, and that the magnitude of these effects among women did not significantly differ from their effects among men. The results of the present study further suggested that the substantial covariation between $C D$ and $A D$ in both men and women was largely due to the influence of genes that increase the risk for both disorders. In the best-fitting model, $76 \%$ and $71 \%$ of the phenotypic association between $C D$ and $\mathrm{AD}$, in men and women respectively, was due to genes that are common risk factors for the two disorders. The remaining $24 \%$ and $29 \%$ of the association in men and women was due to nonshared, or individual-specific, environmental risk factors common to $C D$ and $A D$ risk. Genetic influences common to $C D$ and $\mathrm{AD}$ liability accounted for $17 \%$ and $35 \%$ of the genetic variation in liability to $D S M-I I I-R \mathrm{AD}$ in men and women, respectively, and accounted for $11 \%$ and $23 \%$ of the total variation in $\mathrm{AD}$ liability in men and women, respectively. The results of this study suggest that $\mathrm{CD}$ and $\mathrm{AD}$ are not etiologically or genetically distinct disorders - they share common genetic risk factors that account for most of the observed association between the disorders. The magnitude of the genetic correlation between $\mathrm{CD}$ and $\mathrm{AD}$ liability was at least as high among women as among men.

The results of the present study are broadly consistent with the results of several twin studies that have examined the causes of covariation between antisocial behavior disorders and $A D$, but at first our results appear to contradict the findings of adoption studies that have concluded that antisocial behavior disorders and $\mathrm{AD}$ are etiologically distinct. The reason for the discrepancy between findings from the adoption and twin studies may be that twin studies are more powerful than adoption studies for detecting genetic covariation between traits (Carey \& DiLalla, 1994). The power to detect cross-transmission (i.e., a significant association between one trait in an individual and another trait in a relative) is usually weaker than the power to detect familial transmission for a single trait. Power is further reduced when dyads of relatives are not very closely related genetically. In adoption studies, one examines genetic crosstransmission between first degree relatives, who share an average of one half of their genes. In many cases, especially when sample sizes are not particularly large, there may be insufficient power to detect an important genetic association between two traits in first degree relatives. Twin studies have added power for investigating the genetic covariation between traits because of the inclusion of $\mathrm{MZ}$ twins, who are genetically identical (Carey \& DiLalla, 1994).

Another advantage of twin studies over adoption and family study designs for examining the genetic covariation between traits is that statistical power may be greater when relatives belong to the same generation or birth cohort (e.g., twins or siblings) compared with relatives belonging to different birth cohorts (e.g., parent and offspring), because there may be secular trends for a disorder, such that different genes are relevant for a trait in different generations. The discrepancy between the twin and adoption studies examining the cotransmission of antisociality and $\mathrm{AD}$ is most likely due to differences in statistical power in the study designs.

Other studies (e.g., Lyons et al., 1995) have not found evidence of significant genetic influences for symptoms of $C D$ and thus cast some doubt on the replicability of these results. Followup analyses of the association between $C D$ and $A D$ in the Vietnam era twin sample of Lyons et al. (1995) yielded substantial genetic and shared environmental correlations between CD and $A D$, but because of the imprecision of the estimates of the correlations, the source of the coaggregation of $C D$ and $A D$ (i.e., to what extent it was due to genes or family environment) was not resolvable (True et al., 1997). Consistent across the present study, the study of True et al. (1997), and a recent family study by Stallings et al. (1997) is the conclusion that familial factors are primarily responsible for the substantial correlation between $C D$ and $A D$. Additional research may help to clarify 
the role of genes in the etiology of $\mathrm{CD}$ and resolve the inconsistencies in the literature.

\section{Limitations}

The present study should be interpreted in light of two main limitations that may have affected the results. First, the sample used was a volunteer twin register, which likely under-represents those with a history of severe or persisting antisocial behavior. Although it is reasonable to assume that those with CD or ASPD may be more difficult to recruit into psychiatric surveys, studies of more systematically ascertained samples suggest that it may actually be those without symptomatology who are hesitant to participate (Bucholz et al., 1996) and that those with ASPD are not particularly uncooperative (Bucholz et al., 1996; Cottler, Zipp, Robins, \& Spitznagel, 1987). Without systematic ascertainment or suitable population norms, it is difficult to know the extent to which those with antisocial traits were under-represented in the ATR. Nonetheless, with the data that were available, we were able to find little evidence of bias in the sample.

The other main limitation is that the data were cross-sectional, and both $C D$ and $A D$ diagnoses were based on retrospective reports. Although we have demonstrated adequate reliability of the diagnoses, biases in retrospective accounts still may have inflated the observed association between $\mathrm{CD}$ and $\mathrm{AD}$ in the present study or may have inflated the extent to which the association was due to genetic or environmental factors. For example, the significant nonshared environmental correlation between $C D$ and $\mathrm{AD}$ may have been due to correlated error of measurement induced by assessing both disorders at the same time. The advantage of the retrospective method used in the present cross-sectional study is that the association between $\mathrm{CD}$ and $\mathrm{AD}$ could be examined in a sample that is nearly through the age period of risk for both disorders. It will be important to attempt to replicate this study using prospective twin data.

\section{Implications}

The size of a genetic correlation does not have a straightforward interpretation at the molecular genetic level; it is not a good indicator of the number or proportion of susceptibility loci that the disorders have in common (Carey, 1988). The results of the present study are consistent with the view that there is at least one genetic locus that increases the risk for both $C D$ and $A D$ or that $C D$ is a genetically influenced risk factor for $A D$. The former interpretation is supported by recent research in which a specific genotype was associated with both increased alcohol consumption and aggressive behavior in mice (Crabbe et al., 1996).

Future research should be aimed at identifying those genetically influenced risk factors that contribute to the development of both $\mathrm{CD}$ and $\mathrm{AD}$. Many of the personality correlates of $\mathrm{AD}$ are also correlates of ASPD (Sher \& Trull, 1994). For example, several personality dimensions that are correlated with a history of AD in adults (McGue, Slutske, Taylor, \& Iacono, 1997) aggression, social alienation, and impulsivity - are also correlated with a history of $\mathrm{CD}$ and delinquency in adolescents (Krueger et al., 1994; Krueger, Caspi, Moffitt, Silva, \& McGee, 1996). In addition, the verbal-language-skills deficits found in delinquent youth (Moffitt, 1993) are also found in young adults at risk for $\mathrm{AD}$ (Drejer, Theilgaard, Teasdale, Schulsinger, \& Goodwin, 1985; Sher, Walitzer, Wood, \& Brent, 1991).

Although the correlation between $C D$ and $A D$ was mostly due to genetic factors, there was also a significant correlation between the individual-specific environmental risk factors for $\mathrm{CD}$ and $\mathrm{AD}$. In fact, the hypothesis that the nonshared environmental risk factors for the two disorders were perfectly correlated in women could not be rejected. Common nonshared environmental risk factors for $\mathrm{CD}$ and $\mathrm{AD}$ could be any characteristic or experience unique to an individual, that is, those not shared by a twin and her cotwin, such as different peer groups, school experiences, treatment by parents, and stressful or traumatic life events (see Rodgers, Rowe, \& Li, 1994).

The temporal association between $\mathrm{CD}$ and $\mathrm{AD}$ suggests that $C D$ may be an important pathway through which the common genetic liability for $C D$ and $A D$ increases the risk for the development of $\mathrm{AD}$. Cross-sectional epidemiological surveys (e.g., Kessler et al., 1996) have shown that the onset of CD usually precedes the onset of $\mathrm{AD}$, and longitudinal studies have confirmed this temporal association (Robins, Bates, \& O'Neal, 1962; Vaillant \& Milofsky, 1982; Zucker \& Gomberg, 1986). The within-twin and familial associations between $C D$ and $A D$ in the present study were similar regardless of whether the ageof-onset criterion for $C D$ was less than 18 or less than 15 years, and there was minimal temporal overlap in $\mathrm{CD}$ with an onset prior to age 15 and the onset of $\mathrm{AD}$ (or heavy alcohol use). Therefore, the hypothesis that $\mathrm{CD}$ causes $\mathrm{AD}$ is more plausible than the hypothesis that $A D$ causes $C D$ or that the association between $C D$ and $A D$ is spurious. Of course, temporal ordering is a necessary but not sufficient condition for inferring that $C D$ causes $\mathrm{AD}$. Under certain restricted circumstances, for example, when one trait is largely influenced by genetic factors and the other is largely influenced by family environmental factors, structural equation models fitted to twin and family data can provide information about the direction of causation of the association between two traits (Carey \& DiLalla, 1994; Duffy \& Martin, 1994; Heath et al., 1993; Neale \& Kendler, 1995). With data from the present study, these models were not able to resolve the direction of causation of the association between $\mathrm{CD}$ and $\mathrm{AD}$. The observed correlations were nearly as consistent with the hypothesis that $A D$ causes $C D$ as with the hypothesis that $\mathrm{CD}$ causes $\mathrm{AD}$.

A promising area of future research would be to determine more precisely the mechanisms by which $\mathrm{CD}$ itself may act as a risk factor for $\mathrm{AD}$. It is clear that $\mathrm{CD}$ increases the probability of alcohol and drug use (Boyle et al., 1993; Lynskey \& Fergusson, 1995; Robins \& McEvoy, 1990; Windle, 1990) and decreases the age at which alcohol and drugs are first used (Robins \& McEvoy, 1990). Thus, it appears that youth with CD may be at greater risk for $\mathrm{AD}$ because of increased and earlier exposure to alcohol. In addition, however, $C D$ confers increased risk for the progression to substance abuse even after controlling for exposure and the timing of exposure (Robins \& McEvoy, 1990), and CD also contributes to the maintenance of alcohol abuse among those already evidencing problems (Myers, Brown, \& Mott, 1995). Antisocial behavior disorders may play an important role in the many stages of the development of $A D$, from the initiation of alcohol use to the progression from regular 
drinking to heavy drinking, and in the maintenance and progression of alcohol-related problems. The mechanisms by which this occurs largely remain to be determined.

\section{References}

Amark, C. (1951). A study in alcoholism: Clinical, social-psychiatric and genetic investigations. Acta Psychiatrica et Neurologica, 70, 1283.

American Psychiatric Association. (1987). Diagnostic and statistical manual of mental disorders (3rd ed., rev.). Washington, DC: Author.

Boyle, M. H., Offord, D. R., Racine, Y. A., Fleming, J. E., Szatmari, P., \& Links, P. S. (1993). Predicting substance use in early adolescence based on parent and teacher assessments of childhood psychiatric disorder: Results from the Ontario Child Health Study follow-up. Journal of Child Psychology and Psychiatry, 34, 535-544.

Bucholz, K. K., Cadoret, R., Cloninger, C. R., Dinwiddie, S. H., Hesselbrock, V. M., Numberger, J. I., Jr., Reich, T., Schmidt, I., \& Schuckit, M. A. (1994). A new semi-structured psychiatric interview for use in genetic linkage studies: A report on the reliability of the SSAGA. Journal of Studies on Alcohol, 55, 149-158.

Bucholz, K. K., Shayka, J. J., Marion, S. L., Lewis, C. E., Pribor, E. F., \& Rubio, D. M. (1996). Is a history of alcohol problems or of psychiatric disorder associated with attrition at 11-year follow-up? Annals of Epidemiology, 6, 228-234.

Bushman, B. J., \& Cooper, H. M. (1990). Effects of alcohol on human aggression: An integrative research review. Psychological Bulletin, 107, 341-354.

Cadoret, R. J., O'Gorman, T. W., Troughton, E., \& Heywood, E. (1985). Alcoholism and antisocial personality: Interrelationships, genetic and environmental factors. Archives of General Psychiatry, 42, 161-167.

Cadoret, R. J., Troughton, E., \& O'Gorman, T. W. (1987). Genetic and environmental factors in alcohol abuse and antisocial personality. Journal of Studies on Alcohol, 48, 1-8.

Cadoret, R. J., Yates, W. R., Troughton, E., Woodsworth, G., \& Stewart, M. A. (1995). Genetic-environmental interaction in the genesis of aggressivity and conduct disorders. Archives of General Psychiatry, 52, 916-924.

Carey, G. (1988). Inference about genetic correlations. Behavior Genetics, 18, 329-338.

Carey, G., \& DiLalla, D. L. (1994). Personality and psychopathology: Genetic perspectives. Journal of Abnormal Psychology, 103, 32-43.

Cloninger, C. R. (1987). Neurogenetic adaptive mechanisms in alcoholism. Science, 236, 410-416.

Cloninger, C. R., \& Gottesman, I. I. (1987). Genetic and environmental factors in antisocial behavior disorders. In S. A. Mednick, T. E. Moffitt, \& S. A. Stack (Eds.), The causes of crime: New biological approaches (pp. 92-109). Cambridge, England: Cambridge University Press.

Cloninger, C. R., \& Reich, T. (1983). Genetic heterogeneity in alcoholism and sociopathy. In S. S. Kety, L. P. Rowland, R. L. Sidman, \& S. W. Matthysse (Eds.), Genetics of neurological and psychiatric disorders (pp. 145-166). New York: Raven Press.

Cloninger, C. R., Reich, T., \& Guze, S. B. (1978). Genetic-environmental interactions and antisocial behavior. In R. D. Hare \& D. Schalling (Eds.), Psychopathic behavior: Approaches to research (pp. 225237). New York: Wiley.

Cottler, L. B., Zipp, J. F., Robins, L. N., \& Spitznagel, E. L. (1987). Difficult-to-recruit respondents and their effect on prevalence estimates in an epidemiologic survey. American Journal of Epidemiology, 125, 329-339.

Crabbe, J. C., Phillips, T. J., Feller, D. J., Hen, R., Wenger, C. D., Lessov, C. N., \& Schafer, G. L. (1996). Elevated alcohol consumption in mull mutant mice lacking 5- $\mathrm{HT}_{1 \mathrm{~B}}$ serotonin receptors. Nature Genetics, 14 , 98-101.
Crowe, R. R. (1974). An adoption study of antisocial personality. Archives of General Psychiatry, 31, 785-791.

DiLalla, L. F., \& Gottesman, I. I. (1989). Heterogeneity of causes for delinquency and criminality: Lifespan perspectives. Development and Psychopathology, 1, 339-349.

Drejer, K., Theilgaard, A., Teasdale, T. W., Schulsinger, F., \& Goodwin, D. W. (1985). A prospective study of young men at high risk for alcoholism: Neuropsychological assessment. Alcoholism: Clinical and Experimental Research, 9, 498-502.

Duffy, D. L. (1994). Asthma and allergic diseases in Australian twins and their families. Unpublished doctoral dissertation, Queensland University, Brisbane, Australia.

Duffy, D. L., \& Martin, N. G. (1994). Inferring the direction of causation in cross-sectional twin data: Theoretical and empirical considerations. Genetic Epidemiology, 11, 483-502.

Eaves, L. J., Eysenck, H. J., \& Martin, N. G. (1989). Genes, culture and personality: An empirical approach. New York: Academic Press.

Eaves, L. J., Silberg, J. L., Meyer, J. M., Maes, H. H., Simonoff, E., Pickles, A., Rutter, M., Neale, M. C., Reynolds, C. A., Erikson, M. T., Heath, A. C., Loeber, R., Truett, K. R., Hewitt, J. K. (1997). Genetics and developmental psychopathology: 2. The main effects of genes and environment on behavioral problems in the Virginia Twin Study of Adolescent Behavioral Development. Journal of Child Psychology \& Psychiatry \& Allied Disciplines, 38, 965-980.

Eysenck, H. J., Eysenck, S. B. G., \& Barrett, P. (1985). A revised version of the Psychoticism Scale. Personality and Individual Differences, 6, 21-29.

Falconer, D. S. (1965). The inheritance of liability to certain diseases, estimated from the incidence among relatives. Annals of Human Genetics, 29, 51-76.

Goodwin, D. W., Schulsinger, F., Hermansen, L., Guze, S. B., \& Winokur, G. (1973). Alcohol problems in adoptees raised apart from alcoholic biological parents. Archives of General Psychiatry, 28, 238243.

Gottesman, I. I., \& Shields, J. (1967). A polygenic theory of schizophrenia. Proceedings of the National Academy of Sciences, 58, 199-205.

Grove, W. M., Eckert, E. D., Heston, L., Bouchard, T. J., Jr., Segal, N., \& Lykken, D. T. (1990). Heritability of substance abuse and antisocial behavior: A study of monozygotic twins reared apart. Biological Psychiatry, 27, 1293-1304.

Heath, A. C., Bucholz, K. K., Madden, P. A. F., Dinwiddie, S. H., Slutske, W. S., Bierut, L. J., Statham, D. J., Dunne, M. P., Whitfield, J. B., \& Martin, N. G. (1997). Genetic and environmental contributions to alcohol dependence risk in a national twin sample: Consistency of findings in women and men. Psychological Medicine, 27, $1381-1396$.

Heath, A. C., Bucholz, K. K., Slutske, W. S., Madden, P. A. F., Dinwiddie, S. H., Dunne, M. P., Statham, D. B., Whitfield, J. B., Martin, N. G., \& Eaves, L. J. (1994). The assessment of alcoholism in surveys of the general community: What are we measuring? Some insights from the Australian twin panel interview survey. International Review of Psychiatry, 6, 295-307.

Heath, A. C., Cloninger, C. R., \& Martin, N. G. (1994). Testing a model for the genetic structure of personality: A comparison of the personality systems of Cloninger and Eysenck. Journal of Personality and Social Psychology, 66, 762-775.

Heath, A. C., Kessler, R. C., Neale, M. C., Hewitt, J. K., Eaves, L. J., \& Kendler, K. S. (1993). Testing hypotheses about direction of causation using cross-sectional family data. Behavior Genetics, 23, 29-50.

Heath, A. C., Madden, P. A. F., Bucholz, K. K., Slutske, W. S., Bierut, L. J., \& Martin, N. G. (1996, June). Assessing the effects of cooperation bias and attrition in longitudinal psychiatric genetic research. Paper presented at the meeting of the Behavior Genetics Association, Pittsburgh, PA. 
Heath, A. C., Madden, P. A. F., Bucholz, K. K., Slutske, W. S., Bierut, L. J., \& Martin, N. G. (1998). Assessing the effects of cooperation bias and attrition in behavioral genetic research using dataweighting: II. Adjusting for non-random ascertainment using population norms. Manuscript submitted for publication.

Heath, A. C., Madden, P. A. F., Slutske, W. S., Martin, N. G. (1995). Personality and the inheritance of smoking behavior: A genetic perspective. Behavior Genetics, 25, 103-117.

Heath, A. C., \& Martin, N. G. (1992). Genetic differences in psychomotor performance decrement after alcohol: A multivariate analysis. Journal of Studies on Alcohol, 53, 262-271.

Heath, A. C., \& Martin, N. G. (1994). Genetic influences on alcohol consumption patterns and problem drinking: Results from the Australian NH\&MRC twin panel follow-up survey. Annals of the New York Academy of Science, 708, 72-85.

Heath, A. C., Neale, M. C., Hewitt, J. K., Eaves, L. J., \& Fulker, D. W. (1989). Testing structural equation models for twin data using LISREL. Behavior Genetics, 19, 9-35.

Heath, A. C., Slutske, W. S., \& Madden, P. A. F. (1997). Gender differences in the genetic contribution to alcoholism risk and drinking patterns. In R. W. Wilsnack \& S. C. Wilsnack (Eds.), Gender and alcohol (pp. 114-149). New Brunswick, NJ: Rutgers.

Helzer, J. E., Burnam, A., \& McEvoy, L. T. (1991). Alcohol abuse and dependence. In L. N. Robins \& D. A. Regier (Eds.), Psychiatric disorders in America: The Epidemiologic Catchment Area study (pp. 81115). New York: Free Press.

Helzer, J. E., \& Pryzbeck, T. R. (1988). The co-occurrence of alcoholism with other psychiatric disorders in the general population and its impact on treatment. Journal of Studies on Alcohol, 49, 219-224.

Ito, T. A., Miller, N., \& Pollock, V. E. (1996). Alcohol and aggression: A meta-analysis on the moderating effects of inhibitory cues, triggering events, and self-focused attention. Psychological Bulletin, 120, 6082.

Jardine, R., \& Martin, N. G. (1984). Causes of variation in drinking habits in a large twin sample. Acta Geneticae Medicae et Gemellologicae, 33, 435-450.

Jöreskog, K. G., \& Sörbom, D. (1988). PRELIS: A preprocessor for LISREL Mooresville, IN: Scientific Software.

Kendler, K. S., Heath, A. C., Neale, M. C., Kessler, R. C., \& Eaves, L. J. (1992). A population-based twin study of alcoholism in women. Journal of the American Medical Association, 268, 1877-1882.

Kendler, K. S., Walters, E. E., Neale, M. C., Kessler, R. C., Heath, A. C., \& Eaves, L. J. (1995). The structure of the genetic and environmental risk factors for six major psychiatric disorders in women: Phobia, generalized anxiety disorder, panic disorder, bulimia, major depression, and alcoholism. Archives of General Psychiatry, 52, 374383.

Kessler, R. C., Crum, R. M., Warner, L. A., Nelson, C. B., Schulenberg, J., \& Anthony, J. C. (1997). Lifetime co-occurrence of DSM-III-R alcohol abuse and dependence with other psychiatric disorders in the National Comorbidity Survey. Archives of General Psychiatry, 54, 313-321.

Kessler, R. C., Nelson, C. B., McGonagle, K. A., Edlund, M. J., Frank, R. G., \& Leaf, P. J. (1996). The epidemiology of co-occurring addictive and mental disorders in the National Comorbidity Survey: Implications for prevention and service utilization. American Journal of Orthopsychiatry, 66, 17-31.

Krueger, R. F., Caspi, A., Moffitt, T. E., Silva, P. A., \& McGee, R. (1996). Personality traits are differentially linked to mental disorders: A multitrait-multidiagnosis study of an adolescent birth cohort. Journal of Abnormal Psychology, 105, 299-312.

Krueger, R. F., Schmutte, P. S., Caspi, A., Moffit, T. E., Campbell, K., \& Silva, P. A. (1994). Personality traits are linked to crime among men and women: Evidence from a birth cohort. Journal of Abnormal Psychology, 103, 328-338.

Lewis, C. E., Rice, J., \& Helzer, J. E. (1983). Diagnostic interactions: Alcoholism and antisocial personality. Journal of Nervous and Mental Disease, 171, 105-113.

Lynskey, M. T., \& Fergusson, D. M. (1995). Childhood conduct problems, attention deficit behaviors, and adolescent alcohol, tobacco, and illicit drug use. Journal of Abnormal Child Psychology, 23, 281302.

Lynskey, M. T., Fergusson, D. M., \& Horwood, L. J. (1994). The effect of parental alcohol problems on rates of adolescent psychiatric disorders. Addiction, 89, 1277-1286.

Lyons, M. J., True, W., Eisen, S., Goldberg, J., Meyer, J., Faraone, S. V., Eaves, L., \& Tsuang, M. T. (1995). Differential heritability of adult and juvenile antisocial traits. Archives of General Psychiatry, 52, 906915.

Martin, N. G., Oakeshott, J. G., Gibson, J. B., Starmer, G. A., Perl, J., \& Wilks, A. V. (1985). A twin study of psychomotor and physiological responses to an acute dose of alcohol. Behavior Genetics, 15, 305347.

Martin, N. G., Perl, J., Oakeshott, J. G., Gibson, J. B., Starmer, G. A., \& Wilks, A. V. (1985). A twin study of ethanol metabolism. Behavior Genetics, 15, 93-109.

McGue, M., Pickens, R. W., \& Svikis, D. S. (1992). Sex and age effects on the inheritance of alcohol problems: A twin study. Joumal of Abnormal Psychology, 101, 3-17.

McGue, M., Slutske, W., Taylor, J. T., \& Iacono, W. G. (1997). Personality and substance use disorders: I. Effects of gender and alcoholism subtype. Alcoholism: Clinical and Experimental Research, 21, 513520.

Moffitt, T. E. (1993). The neuropsychology of conduct disorder. Development \& Psychopathology, 5, 135-151.

Myers, M. G., Brown, S. A., \& Mott, M. A. (1995). Preadolescent conduct disorder behaviors predict relapse and progression of addiction for adolescent alcohol and drug abusers. Alcoholism: Clinical and Experimental Research, 19, 1528-1536.

Neale, M. C. (1995). Mx: Statistical modeling (3rd ed.). Unpublished software manual, Department of Psychiatry, Medical College of Virginia, Richmond.

Neale, M. C., \& Cardon, L. R. (1992). Methodology for genetic studies of twins and families. Dordrecht, The Netherlands: Kluwer Academic.

Neale, M. C., \& Kendler, K. S. (1995). Multifactorial models of comorbidity. American Journal of Human Genetics, 57, 935-953.

Olsson, U. (1979). Maximum likelihood estimation of the polychoric correlation coefficient. Psychometrika, 44, 443-460.

Pickens, R. W., Svikis, D. S., McGue, M., \& LaBuda, M. C. (1995). Common genetic mechanisms in alcohol, drug, and mental disorder comorbidity. Drug and Alcohol Dependence, 39, 129-138.

Regier, D. A., Farmer, M. E., Rae, D. S., Locke, B. Z., Keith, S. J., Judd, L. L., \& Goodwin, F. K. (1990). Comorbidity of mental disorders with alcohol and other drug abuse: Results from the Epidemiologic Catchment Area (ECA) Study. Journal of the American Medical Association, 264, 2511-2518.

Reich, T., Cloninger, C. R., \& Guze, S. B. (1975). The multifactorial model of disease transmission: I. Description of the model and its use in psychiatry. British Journal of Psychiatry, 127, 1-10.

Robins, L. N., Bates, W. M., \& O'Neal, P. (1962). Adult drinking patterns of former problem children. In D. J. Pittman \& C. R. Snyder (Eds.), Society, culture, and drinking pattems (pp. 395-412). New York: Wiley.

Robins, L. N., \& McEvoy, L. (1990). Conduct problems as predictors of substance abuse. In L. N. Robins \& M. Rutter (Eds.), Straight and devious pathways from childhood to adulthood (pp. 182-204). New York: Cambridge University Press. 
Rodgers, J. L., Rowe, D. C., \& Li, C. (1994). Beyond nature versus nurture: DF analysis of nonshared influences on problem behaviors. Developmental Psychology, 30, 374-384.

Rowe, D. C. (1983). Biometrical genetic models of self-reported delinquent behavior: A twin study. Behavior Genetics, 13, 473-489.

Schulsinger, F. (1972). Psychopathy: Heredity and environment. International Journal of Mental Health, 1, 190-206.

Sher, K. J., \& Trull, T. J. (1994). Personality and disinhibitory psychopathology: Alcoholism and antisocial personality disorder. Journal of Abnormal Psychology, 103, 92-102.

Sher, K. J., Walitzer, K. S., Wood, P. K., \& Brent, E. E. (1991). Characteristics of children of alcoholics: Putative risk factors, substance use and abuse, and psychopathology. Journal of Abnormal Psychology, $100,427-448$.

Slutske, W. S., Heath, A. C., Dinwiddie, S. H., Madden, P. A. F., Bucholz, K. K., Dunne, M. P., Statham, D. J., \& Martin, N. G. (1997). Modeling genetic and environmental influences in the etiology of conduct disorder: A study of 2,682 adult twin pairs. Journal of Abnormal Psychology, 106, 266-279.

Slutske, W. S., True, W. R., Scherrer, J. F., Goldberg, J., Bucholz, K. K., Heath, A. C., Henderson, W. G., Eisen, S. A., Lyons, M. J., Tsuang, M. T. (1998). Long-term reliability and validity of alcoholism diagnoses and symptoms in a large national telephone interview survey. Alcoholism: Clinical and Experimental Research, 22, 553-558.

Spitznagel, E. L., \& Helzer, J. E. (1985). A proposed solution to the base rate problem in the kappa statistic. Archives of General Psychiatry, 42, $725-728$.

Stallings, M. C., Cherny, S. S., Young, S.E., Miles, D. R., Hewitt, J. K., \& Fulker, D. W. (1997). The familial aggregation of depressive symptoms, antisocial behavior, and alcohol abuse. American Joumal of Medical Genetics (Neuropsychiatric Genetics), 74, 183-191.

Stewart, M., deBlois, S., \& Cummings, C. (1980). Psychiatric disorder in the parents of hyperactive boys and those with conduct disorder. Journal of Child Psychology, Psychiatry, and Allied Disciplines, 21, 283-292.

True, W. R., Heath, A. C., Scherrer, J. F., Xian, H., Lin, N., Eisen, S. A., Lyons, M. J., Goldberg, J., \& Tsuang, M. (1997). Genetic and environmental influences on conduct disorder, alcohol, and marijuana dependence: A multivariate analysis. Unpublished manuscript.

True, W. R., Rice, J., Eisen, S. A., Heath, A. C., Goldberg, J., Lyons, M. J., \& Nowak, J. (1993). A twin study of genetic and environmental contributions to liability for posttraumatic stress symptoms. Archives of General Psychiatry, 50, 257-264.

Twito, T. J., \& Stewart, M. A. (1982). A half-sibling study of aggressive conduct disorder. Neuropsychobiology, 8, 144-150.

Vaillant, G. E., \& Milofsky, E. S. (1982). The etiology of alcoholism: A prospective viewpoint. American Psychologist, 37, 494-503.

Windle, M. (1990). A longitudinal study of antisocial behaviors in early adolescence as predictors of late adolescent substance use: Gender and ethnic group differences. Journal of Abnormal Psychology, 99, 86-91.

Zucker, R. A., \& Gomberg, E. L. (1986). Etiology of alcoholism reconsidered: The case for a biopsychosocial process. American Psychologist, 41, 783-793.

Received October 15, 1996

Revision received March 5, 1997

Accepted January 8, 1998 